\title{
Applicability of prompt gamma-ray analysis to the initial analysis of the extraterrestrial materials for chemical composition
}

\author{
Mitsuru Ebihara and Yoshiji Oura \\ Department of Chemistry, Graduate School of Science, Tokyo Metropolitan University, Hachioji, Tokyo 192-0397, Japan
}

(Received January 9, 2001; Revised August 31, 2001; Accepted September 7, 2001)

\begin{abstract}
When extraterrestrial materials are returned to the earth by future space missions, these materials are to be subjected to the initial examination. For such purposes, measurements are desired to be done non-destructively. In this study, we investigated the applicability of non-destructive prompt gamma-ray analysis (PGA) for determining chemical composition of the returned materials, focusing on levels of induced radioactivities and the effect on isotopic composition by PGA. Under current conditions applied for the PGA facility at the Japan Atomic Energy Research Institute, essentially no residual radioactivities remain after appropriate cooling, making the same specimen analyzed by PGA usable for further research without any restriction. The effect on isotopic composition by PGA was examined both for neutron-induced reactions and for neutron-induced nuclear fission of ${ }^{235} \mathrm{U}$. No significant effect can be brought by neutron-induced reactions even for some noble gas nuclides such as ${ }^{80} \mathrm{Kr}$ and ${ }^{128} \mathrm{I}$, which can be augmented by $(n, \gamma)$ reactions on neighboring halogens. Neutron-induced nuclear fission reactions of ${ }^{235} \mathrm{U}$ yield essentially no effect on isotopic composition. In addition, PGA has several advantages over other nondestructive analytical methods such as instrumental neutron activation analysis (INAA) and synchrotron radiation X-ray fluorescence (SR-XRF); INAA leaves a significant level of induced-radioactivities and SR-XRF yields less reliable and less accurate values for elemental composition. Judging from these features and characteristics, it is concluded that PGA can be one of the most suitable analytical methods potentially applicable for initial analysis of returned samples from space.
\end{abstract}

\section{Introduction}

Through the space mission in 21 st century, we will be able to obtain a wide variety of extraterrestrial materials for laboratory studies. The elemental composition can be crucial to characterize these materials. When the extraterrestrial materials returned from the space are to be analyzed for their chemical compositions, the following requirements are desired to be fulfilled for analytical methods; (i) high sensitivity, (ii) high accuracy and (iii) non-destructivity for as many elements as possible. In recent years inductively coupled mass spectrometry (ICP-MS) techniques have been increasingly applied in analyzing geochemical samples because of their high sensitivity and rapidness (Lipschutz et al., 2001). They have also become gradually popular in cosmochemistry (e.g., Shinotsuka and Ebihara, 1997). These techniques, however, are destructive and, hence, are not appropriate for the initial examination of extraterrestrial materials returned from space.

Nuclear analytical methods such as neutron activation analysis (hereafter, NAA) and photon activation analysis (hereafter, PAA) can meet some or all of the above requirements. Instrumental NAA (INAA) (e.g., Kong et al., 1996) and instrumental PAA (IPAA) (Ebihara et al., 2000) are basically non-destructive methods and have high sensitivity for many elements. There is, however, a serious disadvantage

Copy right (C) The Society of Geomagnetism and Earth, Planetary and Space Sciences (SGEPSS); The Seismological Society of Japan; The Volcanological Society of Japan; The Geodetic Society of Japan; The Japanese Society for Planetary Sciences. for these nuclear methods. As samples are irradiated with reactor neutrons for INAA or high energy photons produced by an accelerator for IPAA, radioactivity induced in these materials becomes fairly high and prevents the irradiated samples from being subjected for other researches such as petrographic and mineralogical examinations.

Neutron-induced prompt gamma-ray analysis (hereafter, PGA) is broadly grouped into NAA but has fairly different characteristics in many aspects. In conventional NAA like INAA, gamma-rays (called decay gamma-rays) emitted with transition from excited levels to lower energy levels of decayed nuclides are measured for most cases while gammarays emitted by neutron-capturing nuclides are measures in PGA. These gamma-rays named prompt gamma-rays or capture gamma-rays are emitted instantaneously (within $10^{-14} \mathrm{~s}$ ) upon capturing of neutrons. In INAA, samples are irradiated in an irradiation tube installed inside the reactor core and, hence, the sample size has a strict limitation. The neutron flux in INAA is rather high, generally in a range of $10^{12}$ to $10^{14} \mathrm{~cm}^{-2} \mathrm{~s}^{-1}$. In PGA, neutrons are guided out of the reactor thorough guide tubes to the beam hall commonly adjacent to the reactor room, which allows large samples to be analyzed (Nakahara et al., 2000). The neutron flux in PGA is considerably low compared with that of INAA, being in $10^{7}$ to $10^{8} \mathrm{~cm}^{-2} \mathrm{~s}^{-1}$ for most cases. Therefore, the induced radioactivity is thought to be low enough for samples to be reused for further investigations. In spite of low neutron flux or fluence in PGA, not a few elements including 
Table 1. Induced radioactivity (in $B q$ ) for $1 \mathrm{mg}$ of some elements by PGA*.

\begin{tabular}{|c|c|c|c|c|c|c|}
\hline \multirow[t]{2}{*}{$\begin{array}{l}\text { Target } \\
\text { nuclide }\end{array}$} & \multicolumn{2}{|c|}{$\begin{array}{l}\text { neutron cross section } \\
\qquad\left(10^{-24} \mathrm{~cm}^{2}\right)\end{array}$} & \multirow[t]{2}{*}{$\begin{array}{l}\text { Produced } \\
\text { nuclide }\end{array}$} & \multirow[t]{2}{*}{ Half life } & \multicolumn{2}{|c|}{$\begin{array}{l}\text { Induced activity }(B q / \mathrm{mg}) \\
\text { at the end of irradiation }\end{array}$} \\
\hline & thermal neu. & cold neu. & & & thermal neu. & cold neu. \\
\hline${ }^{23} \mathrm{Na}$ & 0.68 & 1.5 & ${ }^{24} \mathrm{Na}$ & $15 \mathrm{~h}$ & 19 & 250 \\
\hline${ }^{27} \mathrm{Al}$ & 0.30 & 0.66 & ${ }^{28} \mathrm{Al}$ & $2.3 \mathrm{~min}$ & 160 & 2100 \\
\hline${ }^{45} \mathrm{Sc}$ & 45 & 99 & ${ }^{46} \mathrm{Sc}$ & $84 \mathrm{~d}$ & 5.0 & 65 \\
\hline${ }^{50} \mathrm{Cr}$ & 21 & 45 & ${ }^{51} \mathrm{Cr}$ & $27 \mathrm{~d}$ & 0.27 & 3.5 \\
\hline${ }^{58} \mathrm{Fe}$ & 1.5 & 3.2 & ${ }^{59} \mathrm{Fe}$ & $45 \mathrm{~d}$ & 0.00068 & 0.0088 \\
\hline${ }^{59} \mathrm{Co}$ & 48 & 110 & ${ }^{60} \mathrm{Co}$ & $5.3 \mathrm{y}$ & 0.18 & 2.3 \\
\hline${ }^{151} \mathrm{Eu}$ & 520 & 1100 & ${ }^{152} \mathrm{Eu}$ & $13 \mathrm{y}$ & 0.14 & 1.8 \\
\hline${ }^{191} \mathrm{Ir}$ & 1200 & 2600 & ${ }^{192} \mathrm{Ir}$ & $74 \mathrm{~d}$ & 13 & 170 \\
\hline
\end{tabular}

*Under the following conditions: Irradiation time $=1 \mathrm{~h}$; Thermal neutron flux $=2.4 \times 10^{7} \mathrm{~cm}^{-2} \mathrm{~s}^{-1}$; Cold neutron flux $=1.4 \times 10^{8} \mathrm{~cm}^{-2} \mathrm{~s}^{-1}$; Mean energy of thermal neutron $=15 \mathrm{meV}$; Mean energy of cold neutron $=3.0 \mathrm{meV}$.

Table 2. Induced radioactivity (in $B q$ ) in $1 \mathrm{~g}$ of chondritic meteorite by PGA*.

\begin{tabular}{|c|c|c|c|c|c|c|}
\hline \multirow[t]{2}{*}{$\begin{array}{l}\text { Target } \\
\text { nuclide }\end{array}$} & \multirow[t]{2}{*}{$\begin{array}{l}\text { Produced } \\
\text { nuclide }\end{array}$} & \multirow[t]{2}{*}{ Half life } & \multicolumn{2}{|c|}{$\begin{array}{l}\text { Induced activity }(B q / g) \\
\text { at the end of irradiation }\end{array}$} & \multicolumn{2}{|c|}{$\begin{array}{l}\text { Induced activity }(B q / g) \\
\text { after } 1 \text { week cooling }\end{array}$} \\
\hline & & & thermal neu. & cold neu. & thermal neu. & cold neu. \\
\hline${ }^{23} \mathrm{Na}$ & ${ }^{24} \mathrm{Na}$ & $15 \mathrm{~h}$ & 95 & 1250 & 0.027 & 0.35 \\
\hline${ }^{27} \mathrm{Al}$ & ${ }^{28} \mathrm{Al}$ & $2.3 \mathrm{~min}$ & 1600 & 21000 & 0 & 0 \\
\hline${ }^{45} \mathrm{Sc}$ & ${ }^{46} \mathrm{Sc}$ & $84 \mathrm{~d}$ & 0.050 & 0.65 & 0.047 & 0.61 \\
\hline${ }^{50} \mathrm{Cr}$ & ${ }^{51} \mathrm{Cr}$ & $27 \mathrm{~d}$ & 1.1 & 14 & 0.92 & 12 \\
\hline${ }^{58} \mathrm{Fe}$ & ${ }^{59} \mathrm{Fe}$ & $45 \mathrm{~d}$ & 0.17 & 2.2 & 0.15 & 2.0 \\
\hline${ }^{59} \mathrm{Co}$ & ${ }^{60} \mathrm{Co}$ & $5.3 \mathrm{y}$ & 0.09 & 1.15 & 0.09 & 1.15 \\
\hline${ }^{151} \mathrm{Eu}$ & ${ }^{152} \mathrm{Eu}$ & $13 \mathrm{y}$ & $1.4 \times 10^{-5}$ & $1.8 \times 10^{-4}$ & $1.4 \times 10^{-5}$ & $1.8 \times 10^{-4}$ \\
\hline${ }^{191} \mathrm{Ir}$ & ${ }^{192} \mathrm{Ir}$ & $74 \mathrm{~d}$ & 0.0078 & 0.10 & 0.0073 & 0.094 \\
\hline
\end{tabular}

*Under the same conditions as those for Table 1. CI chondrite composition (Anders and Grevesse, 1989) was used.

most major elements $(\mathrm{H}, \mathrm{B}, \mathrm{Na}, \mathrm{Mg}, \mathrm{Al}, \mathrm{Si}, \mathrm{S}, \mathrm{Cl}, \mathrm{Ca}, \mathrm{Ti}$, $\mathrm{Mn}, \mathrm{Fe}, \mathrm{Co}, \mathrm{Ni}$ ) can be non-destructively determined (Latif et al., 1999; Latif et al., in preparation).

Since PGA is non-destructive and multi-elemental analysis method, it can be one of the most promising methods applicable for the initial analysis of returned samples by future space missions. Although neutron flux in PGA is much lower than that in INAA, one must be highly concerned with the residual radioactivity after analysis. Another concern is a possible alteration of isotopic composition resulting from neutron capture and neutron fission reactions in PGA. In this study, we aimed to estimate the level of induced radioactivities and effect on isotopic composition in PGA, and evaluate how promisingly PGA can be applied to the initial analysis of the extraterrestrial materials including returned samples by future space missions.

\section{Induced Radioactivity by PGA}

The level of induced radioactivity is the most serious concern after samples are subjected to PGA. Table 1 shows the calculation result of induced radioactivity for several selected elements. In this table, the radioactivity at the end of irradiation was calculated for $1 \mathrm{mg}$ of each element. Elements chosen in Table 1 are representative elements which are easily determined in INAA because of high sensitivity and/or high abundance. Induced radioactivity is calculated as follows;

$$
A=\phi \sigma N\left(1-e^{-\lambda t}\right)
$$

where $A$ is induced radioactivity in $B q$ (= disintegration per second, dps), $\phi$ is neutron flux in $\mathrm{cm}^{-2} \mathrm{~s}^{-1}, \sigma$ is neutron cross section in $\mathrm{cm}^{2}, N$ is the number of target nuclide, $\lambda$ is decay constant and $t$ is irradiation time. $\lambda$ is calculated from half life, $t_{1 / 2}$, using a relationship of $\lambda=\ln 2 / t_{1 / 2}$. Here, we assume one hour irradiation at the PGA facility of JRR-3M reactor, Japan Atomic Energy Research Institute (JAERI), where we can use two guided lines of neutrons having different energy (cold and thermal neutrons). Nominal neutron fluxes (in $\mathrm{cm}^{-2} \mathrm{~s}^{-1}$ ) are $1.4 \times 10^{8}$ and $2.4 \times 10^{7}$ and peak energies (in meV) are 3.0 and 15 for cold neutron and thermal neutron, respectively. As noticed in Table 1, the sensitivity for cold neutron is 13 times higher than that for thermal neutron. Among nuclides listed in Table $1,{ }^{28} \mathrm{Al}$ yields the highest radioactivity in $B q$ per $1 \mathrm{mg}$ of target element at the 


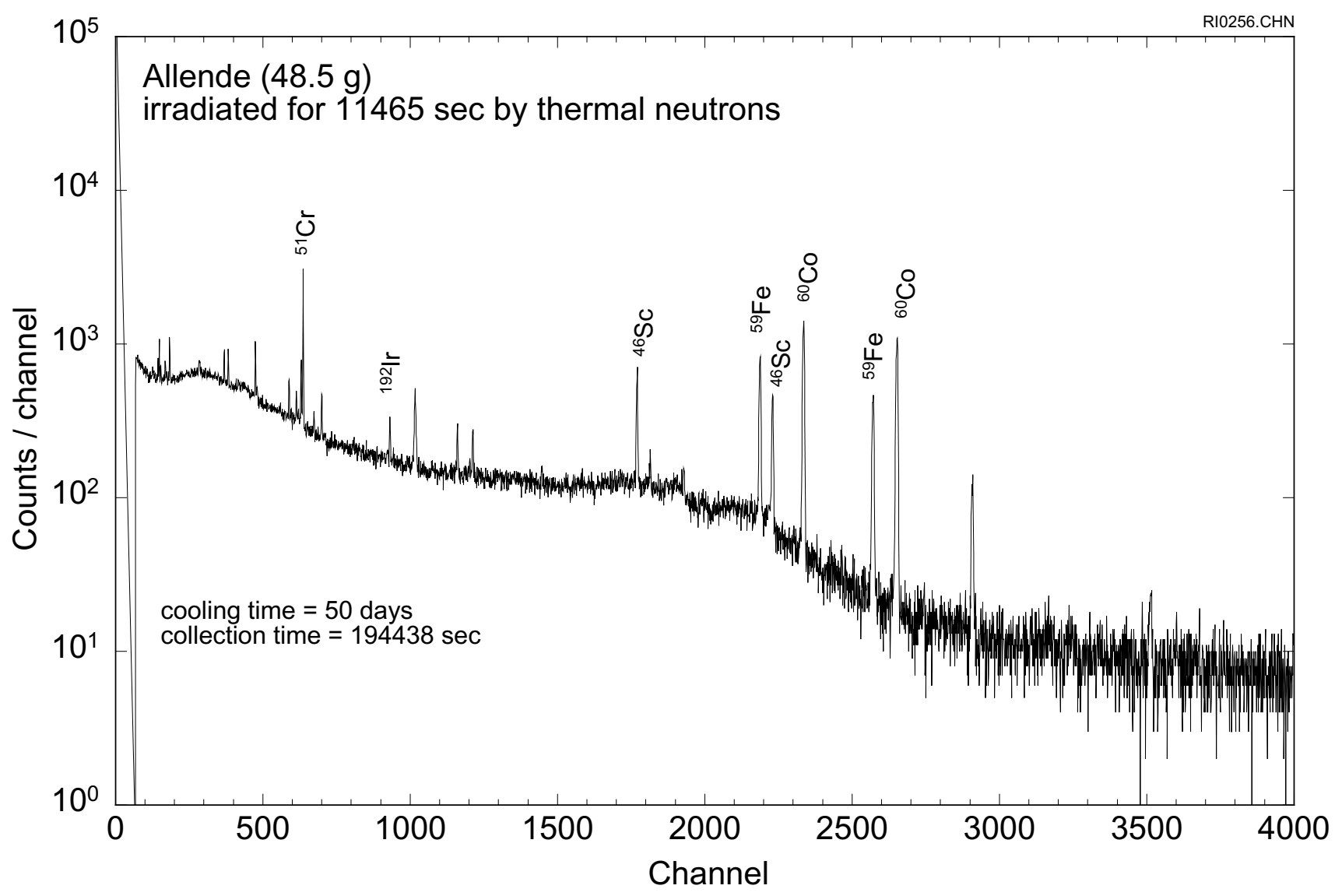

Fig. 1. Gamma-ray spectrum of the Allende meteorite. The specimen (48.5 $\mathrm{g}$ in a lump) was irradiated for $11465 \mathrm{sec}$ with guided beam of thermal neutrons (flux: $2.4 \times 10^{7} \mathrm{~cm}^{-2} \mathrm{~s}^{-1}$ ) at the PGA facility of JRR-3M reactor, JAERI. Measurement was performed for about 2.5 days after 50 days cooling with 10 $\mathrm{cm}$ of $\mathrm{Pb}$ shielding. There appeared several gamma-ray peaks in the spectrum. Many small peaks with no assignment of radionuclides are due to natural radioactivity. Remaining radioactivities induced by PGA are low enough for the specimen to be used for other researches without any legal regulation. 1 channel corresponds to $0.5 \mathrm{keV}$.

end of irradiation. This is because ${ }^{28} \mathrm{Al}$ has the shortest half life among them.

For more practical comparison, induced radioactivities of the same suite of nuclides as listed in Table 1 are compared for amounts of elements contained in $1 \mathrm{~g}$ of chondrite in Table 2. CI chondritic abundances (Anders and Grevesse, 1989) are used as typical composition of chondrite. Induced radioactivities both at the end of irradiation and after 1 week cooling are compared. Irradiation conditions (irradiation time, neutron flux, peak neutron energy) are the same as those for Table 1 . Table 2 shows that only two nuclides, ${ }^{24} \mathrm{Na}$ and ${ }^{28} \mathrm{Al}$, are produced with more than $1000 \mathrm{~Bq}$ for cold neutron at the end of irradiation. After one week cooling, these nuclides mostly decay and ${ }^{51} \mathrm{Cr}$ becomes the most active instead. Nevertheless, the activity of ${ }^{51} \mathrm{Cr}$ after 1 week cooling is much lower than those of ${ }^{24} \mathrm{Na}$ and ${ }^{28} \mathrm{Al}$ at the end of irradiation. Figure 1 shows a gamma-ray spectrum for a large sample (48.5 g) of Allende meteorite measured after 50 days cooling (Latif et al., in preparation). Radionuclides which show prominent peaks are indicated in the figure.

As recognized in Table 2 and Fig. 1, radioactivities induced by PGA remain insignificant even at the end of irradiation and become mostly negligibly small for g-size sample of chondrite if the sample is cooled for an appropriate interval (say, 1 week). This is in sharp contrast with the case for conventional INAA. Once samples are irradiated by neutron for INAA, these samples suffer a strict control for their further use. The samples used for INAA or IPAA cannot be reused for other researches in a regular laboratory from the legal point of view at least in Japan and may only be used for further irradiation for radiochemical NAA study for instance. PGA, however, does not place such a legal restriction.

\section{Effect on Isotopic Composition Induced by PGA 3.1 Neutron capture reactions for nuclides having large neutron cross section}

In addition to the induced radioactivity, effect on isotopic composition also has to be considered when nuclear reactions are involved in analyses. Especially for neutron capture reactions, effect on nuclides having enormously large cross sections may not be able to be ignored. Table 3 summarizes the degree of depletion caused by neutron capture reactions for several nuclides having large cross sections for thermal neutrons. The degree of depletion $(=f)$ is defined as follows;

$$
f=N \phi \sigma t / N=\phi \sigma t
$$

where $N, \phi, \sigma$ and $t$ are the number of target nuclide, neutron flux, neutron capture cross section and time of irradia- 
Table 3. Effect on isotopic composition by neutron-induced reaction by PGA*

\begin{tabular}{|c|c|c|c|c|c|}
\hline \multirow[t]{2}{*}{$\begin{array}{l}\text { Target } \\
\text { nuclide }\end{array}$} & \multirow[t]{2}{*}{$\begin{array}{c}\text { Isotopic } \\
\text { abundance }\end{array}$} & \multicolumn{2}{|c|}{$\begin{array}{l}\text { Neutron cross section } \\
\qquad\left(10^{-24} \mathrm{~cm}^{2}\right)\end{array}$} & \multicolumn{2}{|c|}{ Degree of depletion } \\
\hline & & thermal neu. & cold neu. & thermal neu. & cold neu. \\
\hline${ }^{103} \mathrm{Rh}$ & 1 & 146 & 321 & $1.3 \times 10^{-11}$ & $1.6 \times 10^{-10}$ \\
\hline${ }^{115} \mathrm{In}$ & 0.957 & 161 & 354 & $1.4 \times 10^{-11}$ & $1.8 \times 10^{-10}$ \\
\hline${ }^{149} \mathrm{Sm}$ & 0.138 & 41000 & 90000 & $3.5 \times 10^{-9}$ & $4.5 \times 10^{-8}$ \\
\hline${ }^{151} \mathrm{Eu}$ & 0.478 & 8100 & 1780 & $7.0 \times 10^{-10}$ & $9.0 \times 10^{-9}$ \\
\hline${ }^{153} \mathrm{Eu}$ & 0.522 & 400 & 880 & $3.5 \times 10^{-11}$ & $4.4 \times 10^{-10}$ \\
\hline${ }^{155} \mathrm{Gd}$ & 0.1480 & 61000 & 134000 & $5.3 \times 10^{-9}$ & $6.6 \times 10^{-8}$ \\
\hline${ }^{157} \mathrm{Gd}$ & 0.1565 & 255000 & 561000 & $2.2 \times 10^{-8}$ & $2.8 \times 10^{-7}$ \\
\hline${ }^{164}$ Dy & 0.282 & 4700 & 10300 & $4.1 \times 10^{-10}$ & $5.2 \times 10^{-9}$ \\
\hline${ }^{167} \mathrm{Er}$ & 0.2295 & 670 & 1500 & $5.9 \times 10^{-11}$ & $7.7 \times 10^{-10}$ \\
\hline${ }^{168} \mathrm{Yb}$ & 0.0013 & 3200 & 7040 & $2.8 \times 10^{-10}$ & $3.5 \times 10^{-9}$ \\
\hline${ }^{176} \mathrm{Lu}$ & 0.0260 & 2060 & 4530 & $1.8 \times 10^{-10}$ & $2.3 \times 10^{-9}$ \\
\hline${ }^{174} \mathrm{Hf}$ & 0.0016 & 390 & 860 & $3.4 \times 10^{-11}$ & $4.3 \times 10^{-10}$ \\
\hline${ }^{184} \mathrm{Os}$ & 0.00020 & 3000 & 6600 & $2.6 \times 10^{-10}$ & $3.3 \times 10^{-9}$ \\
\hline${ }^{191} \mathrm{Ir}$ & 0.3773 & 1540 & 3370 & $1.3 \times 10^{-10}$ & $1.7 \times 10^{-9}$ \\
\hline${ }^{196} \mathrm{Hg}$ & 0.0015 & 3120 & 6860 & $2.7 \times 10^{-10}$ & $3.5 \times 10^{-9}$ \\
\hline
\end{tabular}

*Under the same condition as those for Table 1.

tion, respectively. Irradiation conditions are assumed to be the same as those for Tables 1 and 2. Some REE nuclides such as ${ }^{155} \mathrm{Gd}$ and ${ }^{157} \mathrm{Gd}$ have anomalously large values of cross section for neutron capture reactions. Even for these nuclides, however, the degree of depletion induced by neutron capture in PGA is smaller than $10^{-6}(0.01 \epsilon)$, which is too small to be detected by mass spectrometry.

Neutron capture reactions also yield enrichment of corresponding nuclides in accordance with depletion of target nuclides. Here, corresponding nuclides mean neutron-captured nuclides if they are stable, or decayed nuclides if neutron capture nuclides are radioactive. Neutron capture effects leading to both depletion of target nuclides and enrichment of corresponding nuclides are detected for Sm and Gd in lunar surface rocks (Hidaka et al., 2000a) and meteorite samples (Hidaka et al., 1999, 2000b). According to these studies, thermal neutron fluence (total neutron flux; $\phi t$ in formula (1)) larger than $10^{15}$ is necessary for capture effects to be positively detected by thermal ionization of mass spectrometry. One hour irradiation of cold neutrons at the PGA facility of JRR-3M yields a neutron fluence of $5 \times 10^{11} \mathrm{~s}^{-1}$. Even if a sensitivity is increased by a factor of 2.2 for cold neutrons, there still remain a difference of an order of 3 or more.

\subsection{Neutron capture reactions for nuclides producing noble gases}

Noble gas abundances in meteorites are generally very low compared with abundances of neighboring elements mainly because of their high volatility. Therefore, if neutron-captured nuclides decay to noble gases, their contributions may become relatively more significant than those considered in Table 3. Table 4(a) summarizes the production rate of some noble gas nuclides contributed by neu- tron capture $(n, \gamma)$ reactions on corresponding halogens in PGA. Because of large neutron cross sections of ${ }^{81} \mathrm{Br}$ and ${ }^{127} \mathrm{I},{ }^{82} \mathrm{Kr}$ and ${ }^{128} \mathrm{Xe}$ are effectively produced compared with other noble gas nuclides concerned. Combining values in Table 4(a) with halogen and noble gas element contents in meteorites, contributions to noble gases by neutron capture reactions on halogens are estimated for four different types of chondrites in Table 4(b). Although, like noble gas elements, halogens are cosmochemically grouped into volatile elements, their contributions to noble gases are variable; the contribution of $\mathrm{F}$ to ${ }^{20} \mathrm{Ne}$ is the least significant, which is followed by that of $\mathrm{Cl}$ to ${ }^{38} \mathrm{Ar}$. The largest augmentation is found for ${ }^{80} \mathrm{Kr}$ by a reaction of ${ }^{79} \operatorname{Br}(n, \gamma)$. For L chondrites represented by Bruderheim (L6), $\mathrm{Kr}$ is relatively depleted compared with $\mathrm{Br}$, which yields $0.05 \%$ enrichment of ${ }^{80} \mathrm{Kr}$ after $1 \mathrm{~h}$ irradiation of cold neutron at a flux of $1.4 \times 10^{8}$ $\mathrm{cm}^{-2} \mathrm{~s}^{-1}$ (fluence: $5.0 \times 10^{11} \mathrm{~cm}^{-2}$ ). Considering that ${ }^{80} \mathrm{Kr} /{ }^{84} \mathrm{Kr}$ ratios are measured with an error of $1-2 \%(2 \sigma)$ for chondritic meteorites samples, an enrichment of $0.05 \%$ is much smaller that the detection limit. This contribution seems to become even smaller for unequilibrated ordinary chondrites and carbonaceous chondrites, which have higher abundances of $\mathrm{Kr}$ relative to $\mathrm{Br}$ than equilibrated ordinary chondrites like Bruderheim. Thus, it is concluded that no detectable effect is cause in isotopic abundances of noble gas elements by PGA. However, a careful examination may be taken place for the study of isotopic composition of noble gases (especially $\mathrm{Kr}$ and $\mathrm{Xe}$ ) when samples once irradiated with neutron are to be used.

\subsection{Neutron-induced fission reactions of ${ }^{235} \mathbf{U}$}

Neutron-induced fission of ${ }^{235} \mathrm{U}$ can also alter the isotopic composition. Such an effect is dependent upon U contents and/or indigenous abundance of nuclides to which fission 

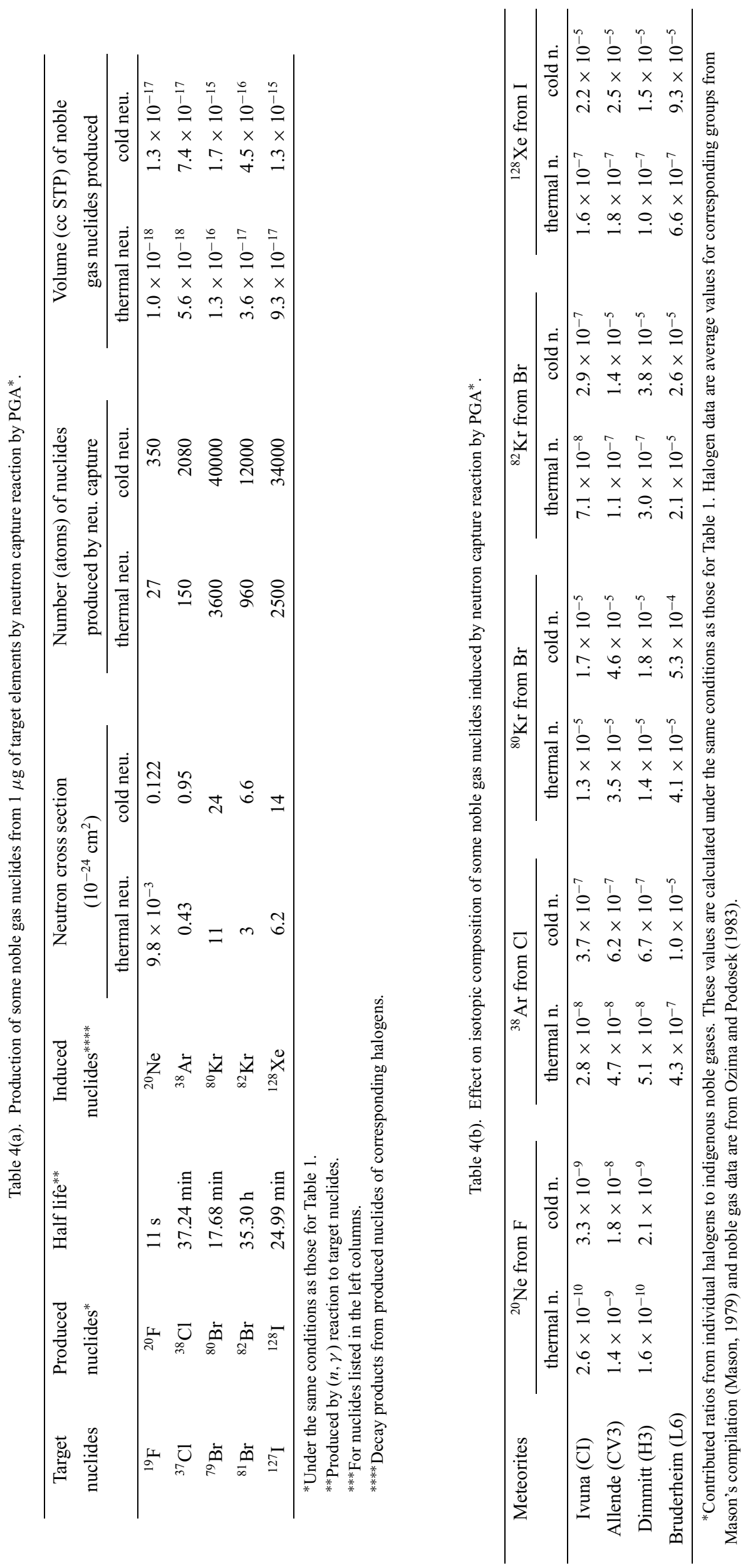
fragments are decayed. Generally, crustal rocks are enriched in large-ion lithophile (LIL) elements such as REE, Th and $\mathrm{U}$ compared with chondritic meteorites. The number of fission fragments from ${ }^{235} \mathrm{U}\left(=n_{f}\right)$ can be calculated as follows;

$$
n_{f}=N \phi \sigma t \times 2
$$

where $N$ is the number of ${ }^{235} \mathrm{U}$ nuclide, $\phi$ is neutron flux, $\sigma$ is cross section for fission cross section by neutron $(585 \times$ $10^{-24} \mathrm{~cm}^{2}$ for thermal neutron) and $t$ is irradiation time.

Let us consider the degree of alteration of isotopic composition caused by neutron-induced nuclear fission of ${ }^{235} \mathrm{U}$ for crustal rocks. Here, we assume that $1 \mathrm{~g}$ of terrestrial basalt with $1 \mathrm{ppm} U$ is irradiated at the PGA facility of JRR-3M. If this sample is irradiated by thermal neutrons for 1 hour at a flux of $2.4 \times 10^{7} \mathrm{~cm}^{-2} \mathrm{~s}^{-1}$, the number of fission fragments is calculated to be 1800 . This number is increased to 23000 for cold neutrons with a flux of $1.4 \times 10^{8} \mathrm{~cm}^{-2} \mathrm{~s}^{-1}$. The largest fission yield for ${ }^{235} \mathrm{U}$ by thermal neutron is $7.87 \%$ for ${ }^{134} \mathrm{Xe}$. Even with this yield, numbers of fissiogenic ${ }^{134} \mathrm{Xe}$ nuclide are 142 and 1810 for thermal neutrons and cold neutrons, respectively, under the assumed conditions.

For the case of chondritic meteorites, these numbers are decreased considerably, because $U$ contents in chondrites are 2 orders of magnitude lower than those in terrestrial basalts. If the $\mathrm{U}$ content is assumed to be $10 \mathrm{ppb}$ for chondrites, all numbers shown above are decreased by a factor of 100 ; numbers of ${ }^{134} \mathrm{Xe}$ nuclide added as fission fragments in $1 \mathrm{~g}$ of chondrites are 1.42 and 18.1 for thermal neutrons and cold neutrons, respectively. Xe content in Allende meteorite is $5.6 \times 10^{-10} \mathrm{ccSTP} / \mathrm{g}$ or $1.5 \times 10^{10}$ atoms $/ \mathrm{g}$. If an isotopic abundance of ${ }^{134} \mathrm{Xe}(0.104)$ is considered, these values fall off down to $5.8 \times 10^{-9} \mathrm{ccSTP} / \mathrm{g}$ and $1.6 \times 10^{9}$ nuclides $/ \mathrm{g}$. It is definitely impossible to detect an addition of 18 to $1.6 \times 10^{9}{ }^{134} \mathrm{Xe}$ nuclides by mass spectrometry of Xe. As Xe is the most depleted element (in ppt) in chondrites among a group of elements whose fission yields from ${ }^{235} \mathrm{U}$ by thermal neutron are larger than $1 \%$, an effect on isotopic composition by neutron-induced fission from ${ }^{235} \mathrm{U}$ in PGA is essentially negligible.

\section{Conclusion}

Assuming that the extraterrestrial materials are returned to the earth by future space missions, we have investigated the applicability of PGA for determining chemical composition of the returned materials. We have examined the level of induced radioactivities and the effect on isotopic composition by PGA under the practical conditions applied for the current PGA facility at the Japan Atomic Energy Research Institute and obtained the following conclusions;

1. Only ${ }^{24} \mathrm{Na}$ and ${ }^{28} \mathrm{Al}$ are produced to a significant level for $1 \mathrm{~g}$ of chondrite at the end of irradiation. After one week cooling, these nuclides mostly decay. Instead, ${ }^{51} \mathrm{Cr}$ becomes relatively the most active, but its level is comparable to those of natural radioactivities such as ${ }^{40} \mathrm{~K}$ and some daughter nuclides of ${ }^{235} \mathrm{U}$ in chondritic meteorites. Thus, no residual radioactivities remain after appropriate cooling, making the same specimen analyzed by PGA usable for further researches without any restriction from practical as well as legal points of view.
2. The effect on isotopic composition by PGA was examined both for neutron-induced reactions and for neutroninduced nuclear fissions from ${ }^{235} \mathrm{U}$. No significant effect can be brought by neutron-induced reactions even for nuclides having anomalously large values of neutron capture cross section such as ${ }^{155} \mathrm{Gd}$ and ${ }^{157} \mathrm{Gd}$.

3. Some noble gas nuclides can be potentially contributed by $(n, \gamma)$ reactions on neighboring halogens. Among them, ${ }^{80} \mathrm{Kr}$ and ${ }^{128} \mathrm{Xe}$ are augmented most largely by neutron irradiation in PGA, but their amounts are much lower than their analytical uncertainties in noble gas spectrometry. Therefore, no detectable effects are caused on isotopic abundances of noble gases by PGA.

4. Neutron-induced nuclear fission reactions by ${ }^{235} \mathrm{U}$ yield essentially no effect on isotopic composition in chondrite samples. This must be also the case for terrestrial igneous rocks, which have relatively high abundance of $U$ compared with chondritic meteorites.

5. In addition to the above features, PGA has several advantages over instrumental neutron activation analysis (INAA) and synchrotron radiation x-ray fluorescence (SR$\mathrm{XRF}$ ); INAA leaves a significant level of induced-radioactivities and SR-XRF yields less reliable and less accurate values for elemental composition. Judging from these features and characteristics, it is concluded that PGA can be one of the most suitable analytical methods potentially applicable for initial analysis of returned samples from space.

Acknowledgments. We are indebted to the reactor committee of the University of Tokyo for cooperative use of the JAERI facility including the PGA facility of JRR-3M. Careful reviews by N. Nakamura and M. E. Lipschutz are acknowledged. This paper was presented at the WPGM meeting held in Tokyo in June, 2000. We are thankful for the session conveners for inviting us to present the paper. This work is supported in part by a Grant-in-Aid of the Ministry of Education, Science and Culture (No. 11440167 to ME).

\section{References}

Anders, E. and N. Grevesse, Abundances of the elements: Meteoritic and Solar, Geochim. Cosmochim. Acta, 53, 197-214, 1989.

Ebihara, M., Y. Oura, T. Ishii, M. Setoguchi, H. Nakahara, and T. Ohtsuki, How effectively is the photon activation analysis applied to meteorite samples, J. Radioanal. Nucl. Chem., 244, 491-496, 2000.

Hidaka, H., M. Ebihara, and S. Yoneda, High fluences of neutrons determined from Sm and Gd isotopic compositions in abubrites, Earth Planet. Sci. Lett., 173, 41-51, 1999.

Hidaka, H., M. Ebihara, and S. Yoneda, Neutron capture effects on Sm, Eu and Gd in lunar regolith, Meteoritics Planet. Sci., 35, 581-589, 2000a.

Hidaka, H., M. Ebihara, and S. Yoneda, Isotopic study for neutron capture effects on Sm and Gd in chondrites, Earth Planet. Sci. Lett., 180, 29-37, 2000b.

Kong, P., M. Ebihara, and H. Nakahara, Precise determination of 18 siderophile elements including all platinum group elements for chondritic metals and iron meteorites by instrumental neutron activation, Anal. Chem., 68, 4130-4134, 1996.

Latif, S. A., Y. Oura, M. Ebihara, G. W. Kallemeyn, H. Nakahara, C. Yonezawa, T. Matsue, and H. Sawahata, Prompt gamma-ray analysis (PGA) of meteorite samples, with emphasis on the determination of $\mathrm{Si}$, J. Radioanal. Nucl. Chem., 239, 577-580, 1999.

Lipschutz, M. E., S. F. Wolf, J. M. Hanchar, and F. Bartow Culp, Geochemical and cosmochemical materials, Anal. Chem., 73, 2687-2700, 2001.

Mason, B., Cosmochemistry, in Data of Geochemistry, edited by M. Fleischer, 132 pp., United States Government Printing Office, Washington, D. C., 1979.

Nakahara, H., Y. Oura, K. Sueki, M. Ebihara, W. Sato, Sk. A. Latif, T. Tomizawa, S. Enomoto, C. Yonezawa, and Y. Ito, Some basic studies on non-destructive elemental analysis of bulky samples by PGA, $J$. Ra- 
dioanl. Nucl. Chem., 244, 405-411, 2000.

Ozima, M. and F. A. Podosek, Noble Gas Geochemistry, 367 pp., Cambridge Univ. Press, Cambridge, 1983.

Shinotsuka, K. and M. Ebihara, Precise determination of rare earth elements, thorium and uranium in chondritic meteorites by inductively cou- pled plasma mass spectrometry - a comparative study with radiochemical neutron activation analysis, Anal. Chem. Acta, 338, 237-246, 1997.

M. Ebihara (e-mail: ebihara-mitsuru@c.metro-u.ac.jp) and Y. Oura 